\title{
Advancing the Growth of Cloud Services in Africa: Trends, Challenges and Opportunities
}

\author{
Omojokun Gabriel Aju \\ Department of Computer Science \\ Adekunle Ajasin University, \\ Akungba-Akoko, Ondo State, Nigeria
}

\author{
Segun Michael Orimoloye \\ Department of Computer Science \\ Adekunle Ajasin University, \\ Akungba-Akoko, Ondo State, Nigeria
}

\begin{abstract}
Cloud computing is growing significantly day by day, and has created a shift in the IT industry. It brings several advantages of having the potential to bolster economic growth through the provision of cost savings and efficiencies by delivering computing as a service, such as self-service, on-demand, broad network access, rapid elasticity, resource pooling, and measured service. Today, individuals and organizations are fast embracing and adopting cloud computing to take advantages that the technology brings. While the growth of the cloud technology is growing exponentially in the North American, European and Far Asian countries, the case of the Africa seem to be difference as the growth rate is at the lowest level. This paper presents the trends and the challenges of advancing the cloud technology and services in Africa with some recommendations on how these challenges can be solved.
\end{abstract}

\section{General Terms}

Cloud Computing, Information Communication Technology

\section{Keywords}

Cloud Computing, Adoption, Africa, ICT, Deployment Model, Network Readiness Index (NRI).

\section{INTRODUCTION}

In recent years, Information and Communication Technology (ICT) has been playing crucial roles in increasing the capability and productivity of organizations, it has invariably become a vehicle of innovations across the industry sectors.

In the evolution process of computing technology, information processing has moved from mainframes to personal computers to server-centric computing to the Web. Today, both individuals and organizations are fast embracing and adopting cloud computing, the present major milestone in computing technology and business collaboration. A supercharged version of delivering hosted services over the Internet, cloud computing potentially enables organizations to increase their business model capabilities and their ability to meet computing resource demands while avoiding significant investments in infrastructure, training, personnel, and software [3].

Cloud computing is a model for enabling convenient, ondemand network access to a shared pool of configurable computing resources (e.g. networks, servers, storage, applications, and services) that can be rapidly provisioned and released with minimal management effort or service provider interaction [1].

The National Institute of Standard and Technology (USA) definition of cloud computing was based on the five essential characteristics, three cloud delivery models, and four cloud deployment models [1]

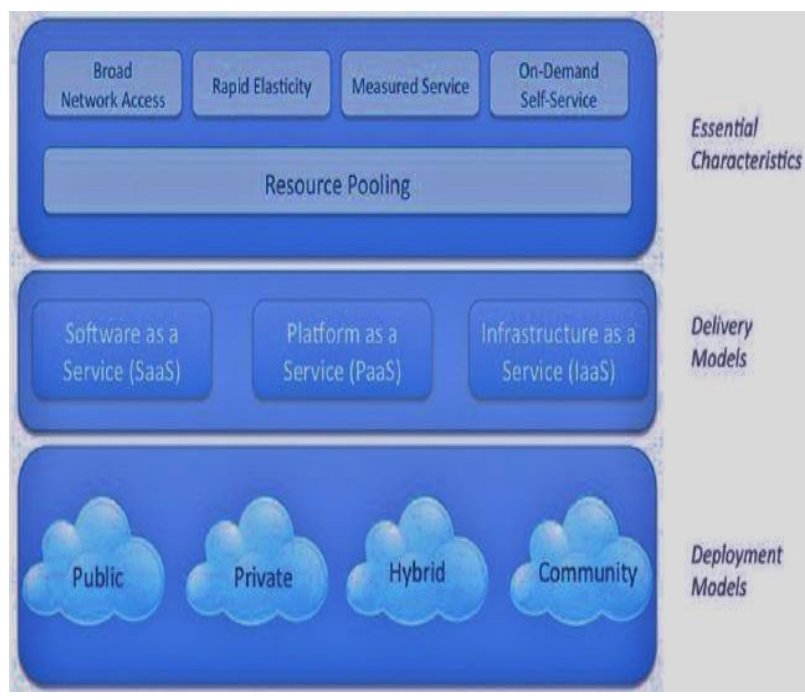

Fig. 1: NIST Visual Model of Cloud Computing Definition

Therefore, cloud computing as an on-demand service model for IT provisioning, often based on virtualization and distributed computing technology is being singled-out as the new trend of ICT development providing scalable, flexible and powerful computing services as if it were utilities such as electricity, gas or water, accessible by anyone, anywhere with an Internet connection. It is therefore not unexpected to see significant global investments being directed toward the cloud computing environment in recent times [5].

Its concepts therefore promise a cost-effective realization of the utility computing principle, allowing the users and providers of cloud services easy access to resources in a selfservice, pay-as-you-go fashion, thus decreasing cost for system administration and improving resource utilization and accounting [4].

Cloud enhances collaboration, agility, scaling, and availability, and provides the potential for cost reduction through optimized and efficient computing. Therefore, cloud computing services offer many benefits when compare to the traditional way of providing computing services, these include [23]:

i. Speed, including faster deployment of software services

ii. Lower computing costs in the form of reduced IT infrastructure expense (including hardware and 
software maintenance costs) as companies pay only for what they use

iii. Reduced dependence on internal IT resources and work on online applications that facilitate collaboration

iv. Accessibility by low-end devices of computational and storage-intensive applications

v. Scalability through on-demand computing and ubiquitous access (multiple networks, remote access, mobile devices)

vi. Improved performance (through the pooling and sharing of hardware resources) and cost-effective security via economies of scale (multiple clients share the cost of enterprise security controls)

\section{THE CLOUD COMPUTING}

The term cloud has been in use since the early 1990s to describe various forms of network such as the popular Asynchronous Transfer Mode (ATM) network. Although, the term came to being in the 1990s, but John McCarthy had in the 1965 conceived the idea that computing infrastructures would be provided to the pubic like other available utilities [2]. It was however Eric Schmidt (The Google' CEO) in 2006 that used the term to describe business model of providing computing services using the already established Internet network, ever since, the term cloud computing has become a standard term for describing the provisioning of computing services through the Internet.

\subsection{Clouds Business Deployment Model}

There are generally four types of cloud computing deployment models with individual entity uniqueness that tend to address specific requirements such as lowering of operation cost, security, performance or reliability.

a) Public clouds: Are clouds in which service providers offer their computing services to the general public. They are easy and inexpensive to deploy because it requires no capital investment on infrastructure and most of the risks involved are transferred to the third party, particularly the infrastructure providers. However, public clouds lack fine-grained control over data, network and security settings, which hampers their effectiveness in many business scenarios as the security policies for the cloud are mostly handle by service providers [6].

b) Private clouds: These clouds are also refers to as internal clouds; the clouds are exclusively designed for the use of a single organization. They may be built and managed by the organization internally or by a third party external provider. They may exist at the organisation's on-premises or off-premises. The greatest benefit is its high level of control over performance, reliability and security. However, they are often criticized for being similar to traditional proprietary server farms and do not provide benefits such as no upfront capital costs.

c) Community Clouds: The clouds infrastructure is shared by a set of organizations of specific community that shared common goals such as security requirements or compliance policy. They may be managed by the organizations or a third party and may exist on-premises or off-premises. d) Hybrid clouds: Hybrid clouds are composition of two or more clouds (private, community, or public) that tries to address the limitations of each approach [16]. Though, the individual cloud retains its unique entities, yet they are bound together by a standardized technology that enables data and application portability.

In a hybrid cloud, part of the service infrastructure runs in private clouds while the remaining part runs in public clouds. Hybrid clouds offer more flexibility than both public and private clouds. Specifically, they provide tighter control and security over application data compared to public clouds, while still facilitating on-demand service expansion and contraction [11]. On the down side, designing a hybrid cloud requires carefully determining the best split between public and private cloud components.

\subsection{Clouds Delivery Model}

Clouds service delivery is divided into three models. The three classifications are mostly referred to as the -SPI Service Model which is represented by Software, Platform and Infrastructure (as a Service) respectively.

a) Software as a Service (SaaS): This service provides the consumers with applications running on a cloud infrastructure. Such applications can be accessible from various client devices through client interface web browser. The underlying cloud infrastructure for the applications such as network, servers, operating systems and storage are not controlled or managed by the consumers but by the service providers. Examples of SaaS providers are Saleforce.com, Hubspot and SAP [9].

b) Platform as a Service (PaaS): This service provides the consumers with platform layer resources such as operating system support and software development frameworks which can be accessed and used through the Internet using programming languages and tools supported by the provider [16]. Although, the consumers does not manage or control the underlying cloud infrastructure like the network, servers, operating systems, or storage, they however has some level of control over the deployed applications and application hosting environment configurations. Examples of PaaS providers are Red Hat, Parallels, Citrix System, Oracle, Google Application Engine [8] and Microsoft Windows Azure [7].

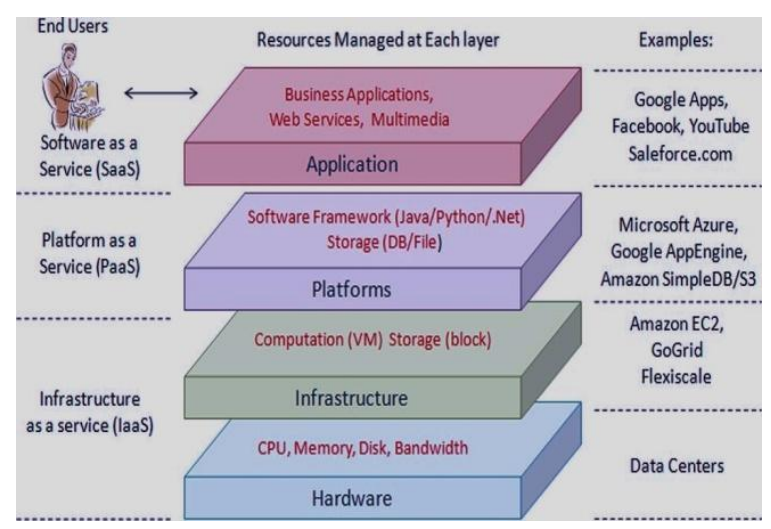

Fig. 2: Cloud Computing Architecture

c) Infrastructure as a Service (IaaS): This service provides the consumers with processing, storage, networks, and other infrastructural computing resources 
that allow consumers to deploy and run software using virtual servers and the service sits at the bottom level of the cloud architectural model. Consumers of these services does not manage or control these underlying cloud infrastructure but has some level of control over the operating systems, storage, deployed applications, and possibly limited control of select networking components (e.g., host firewalls) [10]. Examples of such providers are AT\&T, Rackspace and Equinix.

\subsection{Cloud Computing Related Technology}

Cloud computing has been very evolutionary in nature as its underlying technology have been in existence for several years before the advent of the term "Cloud Computing".

The following technology share some common characteristics and features with the cloud computing. It is therefore acceptable to say that cloud computing is a combination of these already existing technology to produce a coordinated business solutions.

a) Grid Computing: Grid computing is a distributed computing paradigm that coordinates networked resources to achieve a common computational objective. The development of Grid computing was originally driven by scientific applications which are usually computation-intensive [25]. Cloud computing is similar to Grid computing in that it adopts this model to realise its dynamic resources provisioning and sharing.

b) Utility Computing: Utility computing is that model of computing in which computing resources and infrastructure management are provided on-demand and customers are charged based on the resources specific usage rather than a flat rate [18]. Cloud computing also uses this model of utility computing by adopting an ondemand resources provisioning and utility-based pricing scheme for the provided computing resources.

c) Virtualization: Virtualization is a technology that abstracts the details of physical hardware and provides virtualized resources for high-level applications [17]. In order to achieve this technology, a virtualized server is used, otherwise known as a virtual machine (VM). Virtualization forms the foundation of cloud computing, as it inherently adopts the model to pool computing resources from clusters of servers and dynamically allocate virtual resources to applications on-demand.

d) Autonomic Computing: Autonomic computing is a form of computing systems model that is capable of selfmanagement by responding to both internal and external observations without human intervention [19]. The aim of this model is to reduce the human management complexity of present advanced computer system by allowing for systems' self-management. The automatic resources provisioning of the cloud computing adopts autonomic characteristics of the autonomic computing.

Therefore, cloud computing leverages virtualization technology, utility computing, grid computing and autonomic computing features to achieve its goal of providing computing resources in an on-demand model within a shared pools of resources while still holding on to its unique benefits and challenges as a novel computing technology.

\section{WORLD CLOUD SERVICES TRENDS 3.1 Network Readiness Index}

The world has come to a critical tipping point, where the ICTfuelled digital economy is taking off in an exponential way. This has been recognized as the beginning of a Fourth Industrial Revolution that will fundamentally change the way we live, work, and relate to one another. Incidentally, this transformation is not defined by any particular set of technology, but rather by a transition to new ecosystems built on the infrastructure of the digital revolution.

Information and communication technology (ICTs) are now regarded as the backbone of the present industrial revolution. The future of countries, businesses, and individuals depend more than ever on whether they connect to the digital technology that the ICT brings and cloud technology happens to be a major part of these digital technology.

The World Economic Forum's Networked Readiness Index (NRI) which is also referred to as "Technology Readiness" measures the propensity for countries to exploit the opportunities offered by information and communication technology. It is published in collaboration with the European Institute of Business Administration (INSEAD) as part of the annual Global Information Technology Report (GITR) and is regarded as the most authoritative and comprehensive assessment of how ICT impacts the competitiveness and wellbeing of nations.

The countries with the highest cloud technology development are invariably the countries at the top of the world network readiness index league and these countries happen to be the high-income countries in the world.

The composition of the group of top 10 countries in the network readiness index (NRI) for 2016 out of the total of 139 countries consists of a mix of high-income Southeast Asian (Singapore and Japan) and European countries (Finland, Sweden, Norway, the Netherlands, Switzerland, the United Kingdom, and Luxembourg) as well as the United States. Networked readiness therefore remains highly correlated with per capita income. Considering the different elements of networked readiness for these ten countries, it is noticeable that all the ten countries are characterized by very high levels of business ICT adoption [12]. It can therefore be said that there is a relationship between the levels of a country's networked readiness, her cloud technology development and her per capital income.

However, the African countries were at the lowest in the index league suggesting the underdevelopment and low per capital income status of the countries in the region with the Mauritius in $49^{\text {th }}$ position, followed by the South Africa in $65^{\text {th }}$ position while Nigeria and Ethiopia were in the $119^{\text {th }}$ and $120^{\text {th }}$ position respectively [12]. The major factor responsible for the African countries low ranking is the lack of ICT infrastructure, affordability and skills.

Countries are assessed for the network readiness index over four categories of indicators: (1) the overall environment for technology use and creation (political, regulatory, business, and innovation); (2) networked readiness in terms of ICT infrastructure, affordability, and skills; (3) technology adoption/usage by the three groups of stakeholders (government, the private sector, and private individuals); and 
(4) the economic and social impact of the new technology [12].

\subsection{The Cloud Maturity Model}

Countries are segmented using the Cloud Maturity Model based on the levels of cloud adoption by the organizations within these countries. The Cloud Maturity Model identifies four distinct stages of cloud maturity. Denoting cloud adoption by organizations from least to greatest experience, the four stages are [14]:

a) Cloud Watchers: Are organizations that are developing cloud strategies and plans but have not yet deployed applications into the cloud. Cloud Watchers want to evaluate available cloud options and determine which applications to implement in the cloud. A lot of organisations in Africa continent belong to this group.

b) Cloud Beginners: Are new to cloud computing and are working on proof-of-concepts or initial cloud projects [14]. Cloud Beginners want to gain experience with cloud in order to determine future projects. The Africa organizations are dominantly belong to this stage of cloud user as most organizations are optimistic of adopting cloud services are still studying other factors that would influence their final decision of adopting the cloud option.

c) Cloud Explorers: Have multiple projects or applications already deployed in the cloud. Cloud Explorers are focused on improving and expanding their use of cloud resources. The majority of the highly networked countries' organizations in the North America, Asia and Europe belong to this stage of cloud user, while very few of the African countries' organizations can be categorized under this cloud stage. Those few organizations are foreign owned technological and financial organizations with branch offices in Africa.

d) Cloud Focused: Businesses are heavily using cloud infrastructure and are looking to optimize cloud operations as well as cloud costs. The organizations that belong to this cloud stage can mostly be found in the top 10 of the network readiness index countries which are the industrialized countries with high per capital income.

The benefits of the various cloud maturity stages differs between the stages as shown in fig. 3

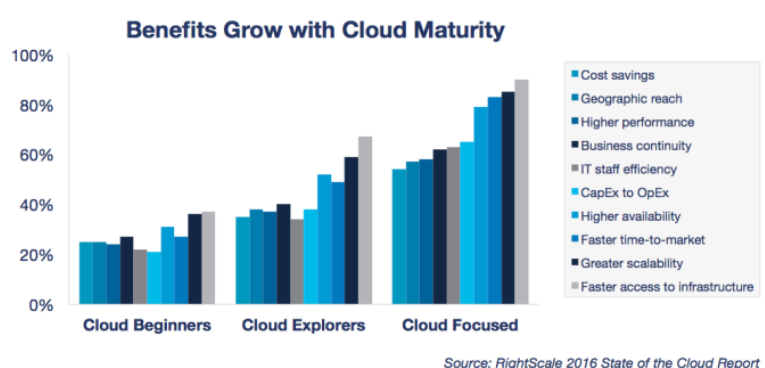

Fig. 3: Benefits Grow with Cloud Maturity

\subsection{World Cloud Spending and Staffing}

The worldwide spending on public cloud services is estimated to grow at a $19.4 \%$ compound annual growth rate (CAGR) from nearly \$70B in 2015 to more than \$141B in 2019, while the spending on public cloud Infrastructure as a Service (hardware and software) is forecast to reach \$61B in 2017, growing to $\$ 173 \mathrm{~B}$ in 2026 [20]. These and many other insights are from the latest series of cloud computing forecasts and market estimates produced by IDC, Gartner, Microsoft and other research consultancies.

The graph in figure 4 provides an overview of spending on public cloud infrastructure worldwide from 2015 to 2026.

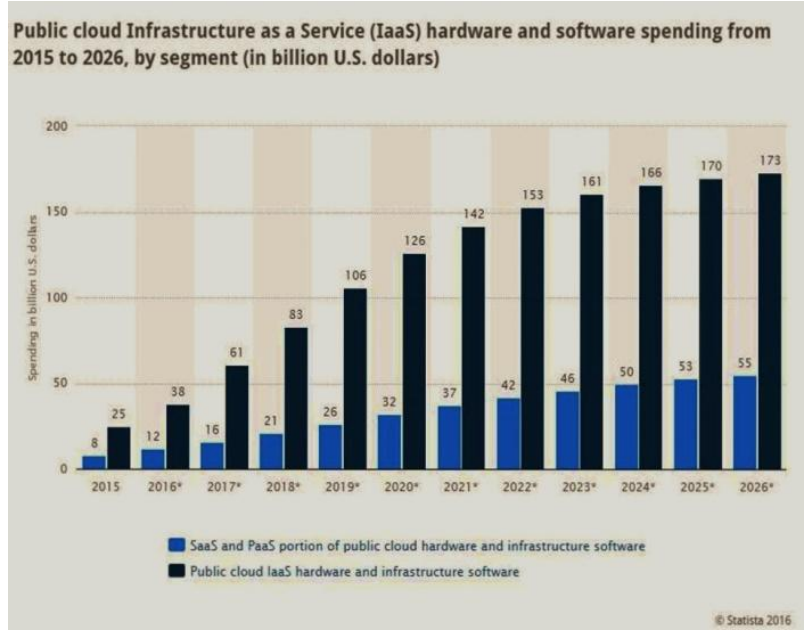

Fig. 4: Public Cloud Infrastructure Forecast

The pattern of spending on the cloud and traditional information technology infrastructure is estimated to experience some changes till 2026 as the cloud infrastructure matures further. The traditional infrastructure hardware and software spending is estimated to drastically reduced from about $\$ 620 \mathrm{~B}$ in 2015 to $\$ 300 \mathrm{~B}$ in 2026 , the Enterprise Information Technology Operational Staffing Costs is also estimated to reduce from around $\$ 300 \mathrm{~B}$ in 2015 to about $\$ 175 \mathrm{~B}$ in 2026. However, the Public Cloud Infrastructure Hardware and Software Spending is expected to increase from $\$ 35 B$ in 2015 to about $\$ 225 B$ in 2026 and the True Private Cloud Spending is also expected to increase from $\$ 7 \mathrm{~B}$ in 2015 to $\$ 200 \mathrm{~B}$ in 2026 [21], signifying that countries and organizations would be investing more on cloud technology.

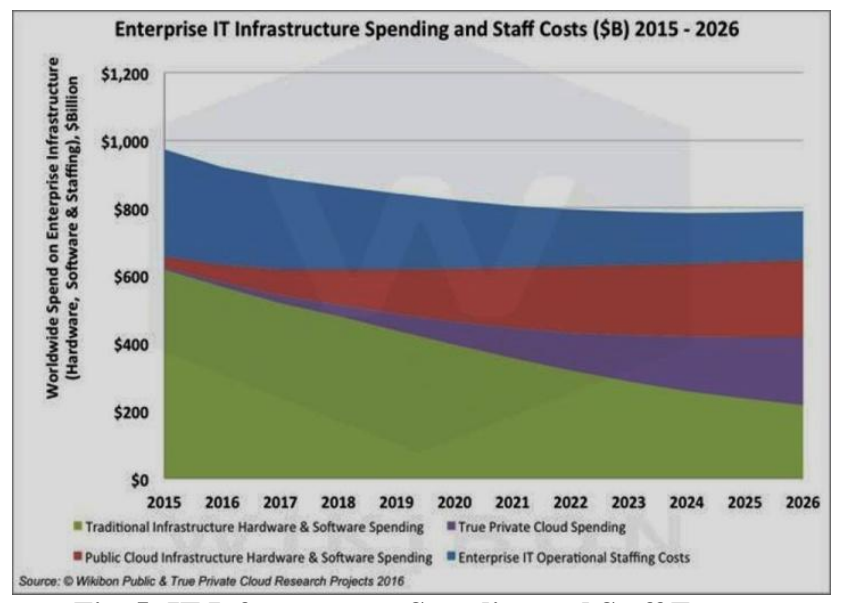

Fig. 5: IT Infrastructure Spending and Staff Forecast

\section{THE CHALLENGES OF CLOUD SERVICES ADOPTION IN AFRICA}

Africa is the world's second-largest and second-mostpopulous continent in the world (the first being Asia) with 54 
countries. At about 30.3 million $\mathrm{km}^{2}$ including adjacent islands, the continent covers $6 \%$ of Earth's total surface area and $20.4 \%$ of its total land area [22]. With 1.248 billion people as of 2016, it accounts for about $16.36 \%$ of the world's human population.

The emergence of cloud computing in Africa is viewed as a natural extension of the deployment of advanced IT technology by high end-users in both the consumer and enterprise service markets. Unfortunately, the advancement rate of this technology is at its lowest level when compare to the North American, European and Asian continents.

The underlying reasons for this low development rate of the cloud services are the problems of limited and uneven development of enabling infrastructure for the delivery of cloud services across the African continent, unavailability of cloud computing experts, high cost of computing equipment, inadequate energy supply, insufficient internet (broadband) infrastructure, economic development, and data security.

\subsection{Security, Privacy and Trust Issues}

The major and most critical challenge surrounding cloud services utilization is security and privacy. The fact that cloud services are offered over internet network where users are able to gain access to computing resources from anywhere makes the services more vulnerable to all forms of cyber-attacks [24].

The real and perceived risks of providing, accessing and controlling services in multitenant cloud environments can slow or preclude the migration of services by IT organizations to the cloud [13]. Since most data centres are located outside the Africa continent, ascertaining the ownership and sovereignty of the data in the data centres can be legally complex.

Data security and privacy is therefore a major cause of underutilization of cloud computing services in Africa. Since service providers typically do not have access to the physical security system of data centres, they must rely on the infrastructure providers to achieve full data security. Even for a virtual private cloud, the service providers can only specify the security setting remotely, without knowing whether it is fully implemented.

\subsection{Inadequate Energy Supply}

Although, the small enterprises and individual users of the cloud in Africa are less concerned with challenges of security and privacy of data as they continue to show optimism in leveraging the potential opportunities that cloud computing presents. However, the inadequate supply of public energy (electricity) in Africa couple with the high cost of providing private energy through the use of private electric generators and solar systems is a factor that has been affecting the full development and utilization of the cloud services by all sectors and institutions in Africa.

The cost of powering and cooling accounts for over $50 \%$ of the total operational expenditure of data centres. In 2015, data centres in the United States consumed more than $5 \%$ of the total energy generated in that year [14]. This shows the importance of energy in the running of data centres which is the backbone of the cloud infrastructures.
As most of the commercial clouds are implemented in large data centres and operated in a centralized mode, although this brings economy-of-scale and high manageability but it also comes with very high energy expense and high initial investment for the construction of the data centres.

The high cost of energy is therefore affecting the development rate of the cloud services as the energy cost is being transferred to the final consumers leading to the cloud services high subscription rate which are mostly rated in United States dollars. Since, most enterprises and individuals are not able to afford this subscription rates, they are forced to seek alternative methods of computing such as making use of the traditional ICT methods. This is greatly in opposite to what is obtained in the advanced countries in Europe, North America and Asia where energy is readily available at affordable rates, forcing the subscription rates of the cloud services to be minimal and therefore increasing the utilization of the services by the enterprises and individuals in those areas and ultimately leading to the more investment on the cloud technology

\subsection{Unavailability of Required Skills}

The architecture and operations of the cloud computing are very different from the traditional information technology services and therefore special skills and expertise are needed to meet these demands in operations and designs. Unfortunately, these skills and expertise are lacking in Africa. For example, while the developed countries have several institutions offering specialized degree programmes in cloud computing and information communication technology (ICT) laws which provide the pools of expertise and skills for the cloud computing technology in the developed countries, such specialized programmes are not available in Africa.

Since these skills are needed for the development of cloud technology in Africa, seeking for such skills from the developed countries will lead to the high cost of recruiting the expatriates for the needed expertise, and this high cost will be transferred to the end-users leading to the high cost of subscription by end-users, this would definitely discourage the intended users of the cloud services as the users may not be able to afford the high cost of accessing the services.

\subsection{High Level of Illiteracy and Low Level of Awareness}

The high rate of illiteracy in Africa is depriving populace from understanding what the cloud technology means and its benefits to the individuals and organizations. So also, those that have the knowledge of cloud technology are unaware of how the services can be accessed or the immeasurable benefits that the technology brings.

The latest report of 2015 from the UNESCO Institute of Statistics ranks Africa as the most illiterate continent on earth with the 19 out of the 25 most illiterate countries coming from Africa continent. Therefore, the inability of the larger percentage of the continent's populace to fully understand the trends and benefits of technology is an impediment to the growth of cloud technology in the region.

\subsection{Lack of Specified Legislation Policy}

Cloud Computing creates new dynamics in the relationship between an organization and its information, as it involves the 
presence of a third party (the cloud providers). This relationship creates new challenges in understanding how laws apply to a wide variety of information management scenarios [15].

Business organizations and individuals are so sceptical about going to the cloud as the legal issues surrounding the cloud services and technology is yet to be established in Africa due to the lack of legislation to legally control the activities of the technology, issues such as, protection requirements for information and computer systems on the cloud, security breach disclosure laws, regulatory requirements, privacy requirements, international boundary requirements, among other are yet to be legislated upon in Africa. Instead the parties involved in the services make use of the Service-Level Agreement (SLA) which in most cases is drafted by the cloud service providers to their advantage because of lack of established legal framework.

Therefore, since there is no unified and legal legislation to protect both the service providers and the consumers, the consumers are always reluctant in the adoption of cloud services for their businesses and storage.

\subsection{Cost of Infrastructure and Equipment}

Africa is considered as a technology backward continent, nearly all the technology equipment needed to establish a cloud infrastructure, particularly the data centres and network infrastructure are manufactured in the developed countries of America, Europe and Asia.

The importation of the equipment increases the cost of these products at the local markets and invariably increases the cost of establishing the cloud infrastructure. As much as these products remain manufactured outside the continent, the cost of accessing cloud services would always be higher compared with the developed countries. And as the cost of accessing this service is excessively higher than what the small and medium enterprise (which makes up the highest percentage of Africa economy) can afford, the utilization rate of the cloud computing services would continue to be low.

\subsection{Poor Quality of Internet Connection}

As the role of cloud services becomes even more important for governments, businesses, and individuals, the high-speed broadband Internet Protocol (IP) networks cannot be overemphasized. Broadband Internet has been termed as one of the world's most important general-purpose technology, with the capability to turn around country's social structures and economies. However, the unavailability and price of terrestrial backbone backhaul networks remain the bottlenecks in broadband uptake in most African countries.

Since cloud services are provided across the internet technology, it is expected that the internet technology of a country should be well developed for such country to enjoy the benefits that clouds give. In the latest World Networked Readiness Index release, no African country is among the first 40 countries. Mauritius is the most networked country in Africa yet it is in the 49th position in the ranking, South Africa in 65 th position while Nigeria is in 119 th position in the world [12].

The implication is that, the internet and information communication technology has not well been developed to meet up with the European, North American and Asian countries. The unavailability of uninterrupted and fast internet technology through broadband services is an impediment to the adoption of cloud services among the populace in Africa.

\section{RECOMMENDATIONS FOR THE CLOUD DEVELOPMENT IN AFRICA}

i. Sub-Africa continent must improve on the provision of adequate and affordable energy by rapidly increasing their energy infrastructure spending. The availability of efficient and affordable energy will reduce the cost of providing large and cost effective data centres which is the major infrastructure needed in the provision of cloud services.

ii. As more organizations are adopting clouds and increasing their data in the clouds to share from the enormous benefits that the technology provides, the need for expertise has tremendously grown requiring more training of IT and cloud development staff within the cloud technology. The knowledge and skills needed in the cloud technology should therefore be given urgent attention by both the governments and business organisations in the continent. Universities and research institutions should be encouraged to incorporate cloud computing technology courses into their curriculum while research groups and laboratories should be established to provide the needed technological, operational and services skills that are presently lacking in the cloud technology sector.

iii. The rate of illiteracy in the continent should also be rapidly reduced by encouraging enrolment of the citizens in the formal education. Awareness of the cloud services should also be created by the institutions and agents of the government by sponsoring programmes that enlighten the public of the benefits of going to the cloud. Public institutions should also be mandated to adopt cloud services for all their ICT resources and services.

iv. Since the cloud services are provided through the internet technology, spending on the internet infrastructure must be embarked upon by the continent particularly in the area of fibre optic cables installations that would connect the whole continent together thereby eliminating the internet connection barriers within the continent. This will definitely increase the performance of the internet services and increase the development of cloud services in the continent.

v. The establishment of Africa cloud computing services legal and regulatory framework will create favourable conditions for the deployment of cloud computing services in the continent. The enactment of continental legislation on data security and privacy in line with global standards will go a long way towards driving development of cloud service as this will give the cloud service providers' legal framework within which data should be handled. This approach will also give the cloud services consumers the required confident to transfer their 
confidential data into the cloud since there is a legal framework that controls the operations of both the providers as well as the consumers.

vi. The critical infrastructure required in the provision of cloud services is the data centres, the infrastructure consist of network equipment, data storage systems, firewall systems, internet servers, cooling systems, among others. The equipment are not presently manufactured in the African continent. The technology organisations should be encouraged by the African governments through various tax incentives to established factories in the continent for the production of the equipment. This will invariably reduce the cost of establishing data centres which will translate to the low cost of providing cloud services to the end-users.

vii. The continent governments' use and promotion of cloud services fall short of their counterparts in the North America, Europe and Far East Asia resulting in the poor ICT infrastructure development in the continent, developing new cloud computing services promotion vision and engagement in the digital economy will lead to rapid growth in the adoption of cloud services in the continent.

\section{CONCLUSION}

Undoubtedly, the long-held dream of conveying computing as a utility has been made possible with the approach of cloud computing. Cloud computing has therefore changed the way organizations offer their computing services to the end-users. It brings several advantages of having the potential to significantly bolster economic growth through the provision of cost savings and efficiencies by delivering computing as a service, such as self-service, on-demand, broad network access, rapid elasticity, resource pooling, and measured service.

Although, the technology has been globally embraced as the major milestone in computing technology and business collaboration that enable organizations to increase their business model capabilities and meeting their computing resource demands while avoiding significant investments in infrastructure which has been pushing countries and organizations to be spending more on the cloud technology infrastructure. It is however unfortunate that the rate of advancement of the cloud technology in the African continent is at a very low level compare to the North American, European and Far Asian countries which are on the top of the world network readiness index (NRI) league. The challenges responsible for the limited and uneven development of enabling infrastructure for the delivery of cloud services across the African continent are the unavailability of cloud computing experts, high cost of computing and network equipment, inadequate energy supply, low internet (broadband) penetration, economic development, and data security.

\section{REFERENCES}

[1] Mell, P., Grance, T. 2009. The NIST Definition of Cloud Computing. National Institute of Standard and Technology. Vol. 53, No.6. Article 50.

[2] Parkhill, D. 1966. The challenge of the computer utility. Addison-Wesley, Reading
[3] Warren, H., Eugene, L., Heidi, P. 2012. Enterprise Risk Management for Cloud Computing. The Committee of Sponsoring Organizations of the Treadway Commission (COSO). Durham.

[4] Lutz, S., Keith, J. 2012. Advances in Cloud: Research in Future Cloud Computing. Commission of the European Communities, Information Society \& Media, Belgium

[5] Jonathan, M., John, Z. 2011. Cloud Computing: Policy Challenges for a Globally Integrated Innovation, Production and Market Platform. Innovia Ventures; School of International Studies, University of California, Berkeley.

[6] Zhang, Q., Cheng, L., Boutaba, R. 2010. Cloud Computing: State-of-the-Art and Research Challenges. Journal of Internet Services and Applications, 1(1), pp.718.

[7] Windows Azure, http://www.microsoft.com/azure. (Accessed: 2 May, 2017)

[8] Google Application Engine, http://code.google.com/appengine. (Accessed: 8 May, 2017)

[9] Dedicated Server, Managed Hosting, Web Hosting by Rackspace Hosting, http://www.rackspace.com

[10] Cloud Security Alliance. 2012. Security Guidance for Critical Areas of Focus in Cloud Computing V3.0. https://downloads.cloudsecurityalliance.org/assets/resear ch/security-guidance/csaguide.v3.0.pdf (Accessed: 7 May, 2017)

[11] Dahiru, A., Bass, M., Allison, I. 2014. Cloud Computing: Adoption Issues for Sub-Saharan Africa Small and Medium Enterprises. Electronic Journal of Information Systems in Developing Countries. Vol. 62, No. 1, pp. 117.

[12] Silja, B., Soumitra, D., Bruno, L. 2016. The Global Information Technology Report 2016: Innovating in the Digital Economy. World Economic Forum, Switzerland. http://www3.weforum.org/docs/GITR2016/WEF_GITR_ Full_Report.pdf (Accessed: 17 May, 2017)

[13] Raghu, Y., Sudhir, R. 2013. Service Security and Compliance in the Cloud. Service Technology Magazine. Issue LXXIII. http://servicetechmag.com/system/application/views/I73/ 0613-5.pdf (Accessed: 12 June, 2017)

[14] RightScale. 2016. State of the Cloud Report. RightScale Inc. http://www.mcit.gov.eg/Upcont/Documents/Reports\%20 and\%20Documents_1252016000_RightScale-2016State-of-the-Cloud-Report.pdf (Accessed: 23 May, 2017)

[15] Wesam, D., Ibrahim, T., Christoph M. 2010. Infrastructure as a service security: Challenges and solutions. The 7th International Conference on Informatics and Systems, 2010, pp. 1-8.

[16] Barros, A., Kylau, U. 2011. Service Delivery Framework-An Architectural Strategy for NextGeneration Service Delivery in Business Network. Proceedings of the 2011 Annual SRII Global Conference, pp. 47-37. 
[17] Virtualization

Computing, https://www.vmware.com/solutions/virtualization.html (Accessed: 3 June, 2017)

[18] Ranjan, K.M, Debabrata, S. 2015. Utility Computing. International Journal of Grid Distribution Computing. Vol. 8, No.4, pp. 115-122

[19] IBM Corporation. 2005. An architectural blueprint for autonomic computing. IBM Corporation, Hawthorne, NY 10532

[20] Statista. 2016. Public cloud Infrastructure hardware and software spending. https://www.statista.com/statistics/507952/worldwidepublic-cloud-infrastructure-hardware-and-softwarespending-by-segment/ (Accessed: 5 July, 2017)

[21] Wikibon. 2016. Sizing the Private Cloud and True Private Cloud Market. https://wikibon.com/public-cloud- iaas-is-3-5x-the-size-of-true-private-cloud-adoption/ (Accessed: 05/07/2017)

[22] Kaneda, T., Bietsch, K. 2016. 2013 World Population Data Sheet. Population Reference Bureau. www.prb.org. (Accessed:18 August, 2017)

[23] Michele, E. 2010. Evaluating Cloud Risk for the Enterprise: A Shared Assessments Guide. The Santa FE Group

[24] Zhifeng, X., Yang, X. 2013. Security and Privacy in Cloud Computing. IEEE Communications Surveys \& Tutorials. Vol. 15, No.2. pp. 843-859.

[25] Fran, B., Geoffrey, F., Anthony, J. G. H. 2003. Grid Computing: Making the Global Infrastructure a Reality. Vol. 2. John Wiley and Sons. 